\title{
Effects of Chinese Economic Stimulus Package on Economic Growth in the Post-Crisis China
}

\author{
Shenglv Zhou, ${ }^{1,2}$ Minjun Shi, ${ }^{1,2} \mathrm{Na} \mathrm{Li,}{ }^{1,2}$ and Yongna Yuan ${ }^{1,2}$ \\ ${ }^{1}$ Graduate University of Chinese Academy of Sciences, No. 19 A, Yuquan Road, Shijingshan District, Beijing 100049, China \\ ${ }^{2}$ Research Center on Fictitious Economy and Date Science, Chinese Academy of Sciences, No. 80, Zhongguancun East Road, \\ Haidian District, Beijing 100190, China \\ Correspondence should be addressed to Minjun Shi, mjshi1964@gmail.com
}

Received 28 April 2011; Accepted 8 June 2011

Academic Editor: James R. Barth

Copyright () 2011 Shenglv Zhou et al. This is an open access article distributed under the Creative Commons Attribution License, which permits unrestricted use, distribution, and reproduction in any medium, provided the original work is properly cited.

This paper aims to simulate the contribution of investment expansion policy after financial crisis as well as describe the possible economic perspectives in the post-crisis period by using scenario simulation method based on Chinese dynamic economic CGE (computable general equilibrium) model. Energy consumption and $\mathrm{CO}_{2}$ emission are also considered in order to access the possible negative effects owing to investment enlargement. The results show that expanding investment response to financial crisis increases economic growth rate by $6.74 \%$ from $2.36 \%$ in 2009 . It can relieve the fluctuation in economy and bring the economic growth close to baseline level in the near post-crisis period. However, higher energy consumption intensity and $\mathrm{CO}_{2}$ emission intensity compared to baseline owing to the increasing investment make energy saving and $\mathrm{CO}_{2}$ mitigation more difficult.

\section{Introduction}

The 2008 financial turmoil, started due to the U.S subprime mortgage crisis, brings world economy into a downturn period. Governments even in the rich countries have had to put forward packages to bail out their economy and society. As for China, the central government has also announced a series of macroeconomic policies to alleviate the negative impact from financial crisis, about practicing the "proactive" fiscal and "moderately loose" monetary policies, about taking 10 various approaches to boost domestic consumer demand, and about acceleration the infrastructure construction and so on.

The 4 trillion stimulus package, which scheduled to be implemented in two years with 1.18 trillion Yuan investment planned by the central government and the remaining provided by the local government and nongovernmental, is expected to mainly cover affordable housing projects, infrastructure construction in rural areas, postdisaster reconstruction, improving people's livelihoods, environmental protection, technological reform and building necessary infrastructure. It is believed that this package plays an important role to maintain a stable and relatively fast growth, with
GDP growth rate achieve $9.6 \%$ and $9.1 \%$ in 2008 and 2009, respectively.

What is the contribution of such a massive investment to economic growth under financial crisis? What is the economy were look like as if there are no such package policies? What will the economic may appear to be in the near term after financial crisis. To quantitative evaluate the policy effects under and after financial crisis can not only answer the above questions we are concerned about, but also has meaningful reference value for future policy development direction.

It can be seen that China gradually has been becoming a typical investment-oriented economy in recent years. Econometric is the most common method to build the relationship between investment and GDP, including $\mathrm{Wu}$ [1], Liu and Yu [2], Wang [3], and Zhang and Hou [4]. These empirical results show that investment plays a significant role in economic growth, while there is a big room for raising the efficiency of investment. Both Wang et al. [5] and Li et al. [6] build multi-regional CGE (computable general equilibrium) model to discuss investment policies on economic development. According to $\mathrm{Li}$ et al. [6], the same amount 
of investment in different regions deserves different GDP growth, with 200 billion of government investment in eastern, central, and northwestern regions drives total GDP to increase by $0.56 \%, 1.38 \%$, and $1.54 \%$, respectively.

A few studies have qualitatively investigated the very likely effects and correlative problems associated with Chinese stimulus package (Ding [7], S. L. Zhang [8], X. P. Zhang [9]). With regard to empirical analysis, Wang and Lu [10] used the national income multiplier theory and pointed out that the 4 trillion investment stimulate policy can achieve the desired effects with the rapid recovery of world economy. It can stabilize the society and economy in the short run, while is less favorable to optimize economic growth pattern. Based on a static multi-regional CGE model analysis, GDP growth rate and employment tend to be higher if investing to central China compared to the whole country or western China (Sun et al. [11]).

This paper aims to simulate the contribution of investment expansion policy to Chinese economic growth by using scenario simulation method based on Chinese dynamic economic CGE model. Moreover, it takes the advantage of dynamic CGE model and attempts to describe the possible economic perspectives in post-crisis period under different scenarios. Furthermore, in contrast with other previous research, allowing for the possible problems of over capacity due to large investment, this study assesses the influence on energy consumption and $\mathrm{CO}_{2}$ emission from enlarging investment.

The rest of the paper is organized as follows: methodology and data are described in Section 2. Section 3 presents the setup of three scenarios considered in the simulation. The results under different scenarios are outlined in Section 4. It is followed by a conclusion in Section 5 .

\section{Methodology and Data}

\subsection{Methodology}

2.1.1. Production Structure of CGE Model. CGE model, which is not only good at describing microeconomic optimization behaviors and mutual relationship among different economic agents, but also analyzing the macroeconomic consequences caused by policy change, has become an effective tool for policy simulation.

The basic dynamic CGE model is built based on the structure from Lofgren's work [12]. In order to assess the policy impact on energy consumption and $\mathrm{CO}_{2}$ emission, energy is treated as production factor and embedded into production module, which refers to the work of $\mathrm{Wu}$ and Xuan [13]. Hence, the input of production can be divided into three factors of capital, labor, and energy as well as nonenergy intermediate commodities (1).

$$
Y_{i}=f_{i}\left(A_{i}, K_{i}, L_{i}, E_{i}, V_{i}\right)
$$

where, $Y_{i}$ denotes output of sector $i, A_{i}$ denotes shift parameter of sector $i$, and $K_{i} L_{i} E_{i} V_{i}$ is the input of capital, labor, energy, and intermediate commodities to sector $i$, respectively.
Since the elasticity of substitution varies among different input, the production is described by multilevel nested structure. Intermediate commodities enter into the model with Leontief structure (2) to reflect the assumption of no substitution among different intermediate commodities as well as between intermediate commodities bundle and factors bundle. The labor-capital-energy bundle derives from a multilevel CES (constant elasticity of substitution) structure (3) among labor, capital and energy. Similarly, energy enters into the model with a multilevel nested structure of the 9 type energy, which including coal, oil, natural gas, oil refined products, coke, fuel gas, thermal electricity, other electricity, and heat. The framework of production module is shown in Figure 1

$$
\text { Leontief function : } \begin{aligned}
Y_{i} & =\min \left(\alpha * X_{i 1}, \beta * X_{i 2}\right), \\
\text { CES function : } \quad Y_{i} & =f\left(X_{i 1}, X_{i 2}\right) \\
& =\left(\alpha * X_{i 1}{ }^{\rho}+\beta * X_{i 2}{ }^{\rho}\right)^{1 / \rho} \\
& =A *\left(\alpha * X_{i 1}{ }^{\rho}+(1-\alpha) * X_{i 2}{ }^{\rho}\right)^{1 / \rho},
\end{aligned}
$$

where, $\alpha$ denotes share parameter of input $X_{i 1}, \beta$ denotes share parameter of input $X_{i 2}$, and $\rho$ denotes substitution parameter.

2.1.2. Other Modules. Economic growth is driven by investment, consumption and net export. Investment is determined by saving which come from household, government, enterprise, and abroad. Household income is used for tax payment, consumption and saving, while government income is expended for transfer payment, subsidy, consumption, and saving. Household and government consumption are codetermined by income and consumption preference, and they are described through the extended linear expenditure system. The Armington assumption is used to distinguish identical domestic goods and imported (exported) goods. World price is exogenous and China is treated as price taker.

It is assumed that returns to scale of all sectors are constant, and the proportion of effective labor force to total population is constant in the simulation period. The modeling of dynamism is realized by capital accumulation, labor growth, and technological improvement. The simulation period is from 2007 to 2015 .

2.2. Data. The basic dataset of this model is China 2007 SAM (Social Accounting Matrix), which is constructed using the 2007 135-sectors input-output table and other data in 2007 including custom, tax, international balance of payment, together with flow of funds. The 135-sectors input-output table is aggregated and disaggregated into 39 sectors, which includes 1 agriculture sector, 36 industry sectors and 2 service sectors.

Substitution elasticity among different energy, energy and capital, energy-capital combination, and labor refers to the research of $\mathrm{Wu}$ and Xuan [13] and MIT-EPPA [14] 


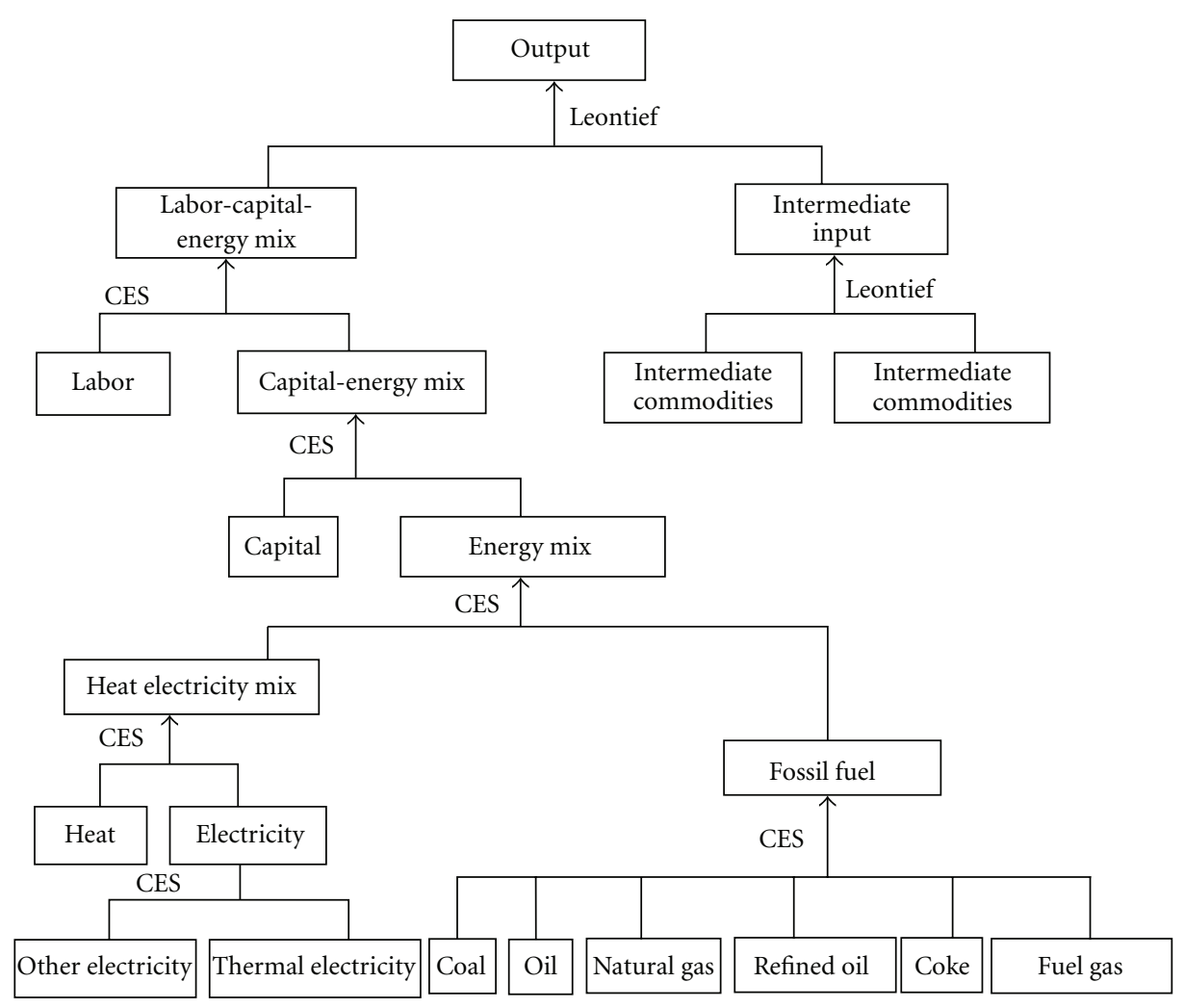

FIGURE 1: Structure of production module in dynamic CGE model.

Substitution elasticity between import and domestic commodities refers to GTAP-6. The data of labor by sectors come from "Fifth Population Census" and "China Economic Census Yearbook 2004". The data of fixed assets investment and population are from "Chinese Statistical Yearbook 2008".

Energy consumption should be treated in physical terms, while the input-output table provides energy consumption in each agent in monetary terms. The base year conversion coefficients (regarded as energy price) can be got from dividing monetary terms to physical terms (China Energy Statistics Yearbook, 2008), which are also used in the forecast of future energy consumption from CGE model. $\mathrm{CO}_{2}$ emissions can be calculated by the method recommended by the IPCC [15]. That is, multiplying each type of fossil fuel consumption with its $\mathrm{CO}_{2}$ emission factors and oxidation rate. Hence, this paper only covers the $\mathrm{CO}_{2}$ emission from fossil fuel.

\section{Scenario Design}

Using the methodology described above, three scenarios have been designed to illustrate the potential economic effects of stimulate packages: the first scenario is a baseline scenario, where it is to describe the Chinese normal economic development trajectory without financial crisis. The second scenario, that is, crisis scenario, shows the economic growth path under crisis without carrying out corresponding policies. The third scenario is the policy scenario that portrays economic growth pathway with implementing positive activ- ities (mainly focus on investment stimulus package) after financial turmoil. Some key parameters are set as follows.

3.1. Baseline Scenario. Besides the parameters which can be calibrated according to the base year data and the elasticity of substitution, annual labor supply, and TFP (total factor productivity) growth rate are exogenous in this model. The existing research show that TFP growth rates mainly distribute in the range of $2 \%$ to $4 \%$ over the past three decades. TFP annual growth rate is estimated by $3.14 \%$ from 1981 to 2002 (Sun and Ren [16]), and 3.63\% during the period of 19992007 (Wang et al. [17]). It is assumed that TFP will not always keep a high level and gradually decline, with a growth rate of $3.2 \%$ in 2008-2010 and 2.8\% from 2011 to 2015.

Commodity price index consumed by household and government refers to CPI historical data. Average value of CPI from 1990-2010 is 104.8 and 102.4 when eliminating the outlier value and here is expected to an average value of 103 during the simulation time. What is more, it is assumed that the proportion of effective labor force to total population is constant in the simulation period.

3.2. Crisis Scenario. The impacts on import and export, as well as productivity due to financial crisis are taken into consideration under crisis scenario. The import-export trade is shocked greatly by the decline of overseas demand and import-export commodities price from the end of 2008. Export price is supposed to drop by $5 \%$ in 2008 and $15 \%$ 
in 2009, together with an assumed reduction rate of $5 \%$ in 2008-2009 for import price. The import and export price are expected to return to the level of 2007 from 2010.

It is supposed that the growth rate of gross fixed capital formation is in line with baseline scenario, with an absolute value of 10.54 trillion, 12.82 trillion and 19.4 trillion Yuan in 2007, 2009, and 2015, respectively. Commodity price index consumed by household and government is influenced by investment and becomes endogenous under crisis scenario.

Some labor forces and capitals are laid aside result in a decline of TFP under financial crisis. The prediction by Wang et al. [17] suggests that TFP growth rate is likely to drop to $1.79 \%$ in 2008-2020 with financial crisis. Hence, TFP growth rate is assumed to $1.8 \%$ in 2009 and gradually restore to the baseline level in 2011.

3.3. Policy Scenario. Policy scenario is aiming to assess the effects of the enlarging investment policy after financial crisis. Actual value of gross fixed capital formation is calculated based on its contribution to GDP in 2008 and 2009. In 2009, the added investment was 5.2 trillion Yuan and the actual fixed capital formation was 2.5 trillion Yuan. From 2010, the growth rate of fixed capital formation is similar with baseline. TFP growth rate is calibrated to $3.1 \%$ and $2.5 \%$ by the real GDP in 2008 and 2009 and supposed to be the same with baseline from 2010. It should be noticed that investment brings a part of inactive labors and capitals back to work again and drives TFP to become higher compared to crisis scenario.

\section{Results}

\subsection{Economic Effects in Different Scenarios}

4.1.1. GDP. GDP is predicted to grow from 27.2 trillion Yuan in 2007 to $52.5,47.8$, and 51.6 trillion Yuan (based on 2007 price) in 2015 under baseline scenario, crisis scenario and policy scenario, respectively (Figure 2). GDP growth rate falls to $2.36 \%$ in 2009 without any corresponding policies affected by financial crisis. It follows by a strong rebound in 2010 and then appears a little lower than baseline. Expanding investment is one of a primary impetus behind economic recovery. It stimulates GDP growth rate up to $9.10 \%$ in 2009 compared to $2.36 \%$ in crisis scenario. The results show that the average annual GDP growth rates during the period of "Chinese twelfth five years plan", that is, from 2011 to 2015, are $7.94 \%, 7.38 \%$, and $7.61 \%$ under baseline scenario, crisis scenario, and policy scenario, respectively. Although GDP growth rate in policy scenario is below baseline from 2011, the gap is becoming smaller and smaller with years roll on (Figure 3). It can be observed that investment can alleviate the great impact on GDP growth and relieve the fluctuation in economy owing to the sharp decrease of overseas demand as well as bring the economic growth into baseline level in the near term gradually.

4.1.2. Import and Export. Figures 4, 5, 6, and 7 display the change of import and export under different scenarios. The annual growth rate of total export in constant price is
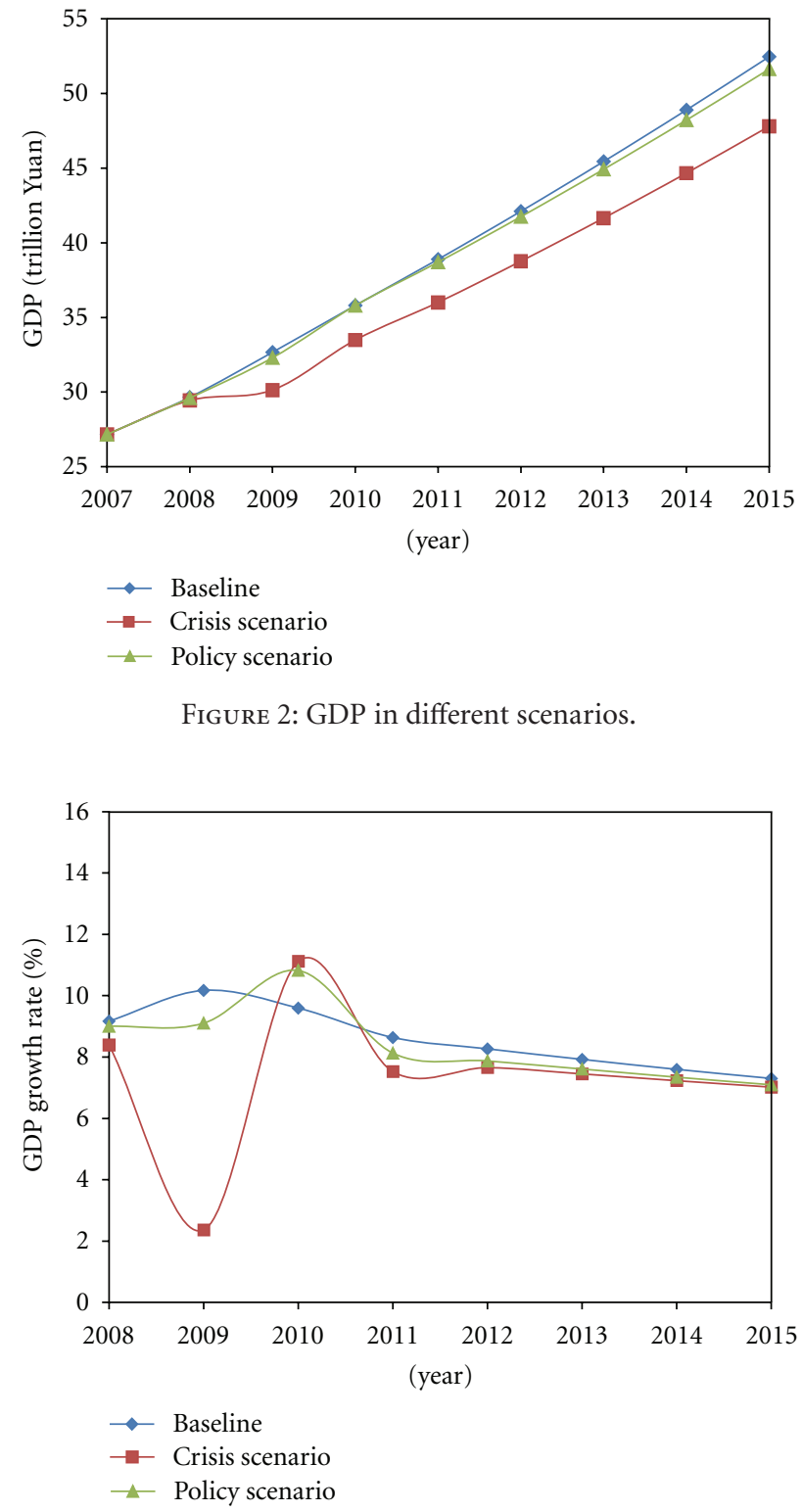

FIGURE 3: GDP growth rate in different scenarios.

approximately $6.2 \%-7.5 \%$, while the total import increases less quickly with an annual growth rate of 5.8\%-7.5\% during the period of 2008-2015 under baseline. Owing to the impact of financial crisis, total export starts to decline from 2008, together with total import and total export experience a sharp slowdown in 2009. The results show that the total export and total import fall by $19.6 \%$ and $5.7 \%$ in 2009 , respectively. Whereas they increase rapidly in 2010 with a growth rate of $33.0 \%$ for total export and $21.7 \%$ for total import from the very low level in 2009 and then following by a steady ascent from 2011. Investment plays an important role in stimulating domestic demand but has a limited influence on international market. Hence, total export and total import also appear negative growth with a drop rate by $17.1 \%$ and $5.3 \%$ in 2009 compared to 2008 , which means that the effects on preventing the decrease of export and 


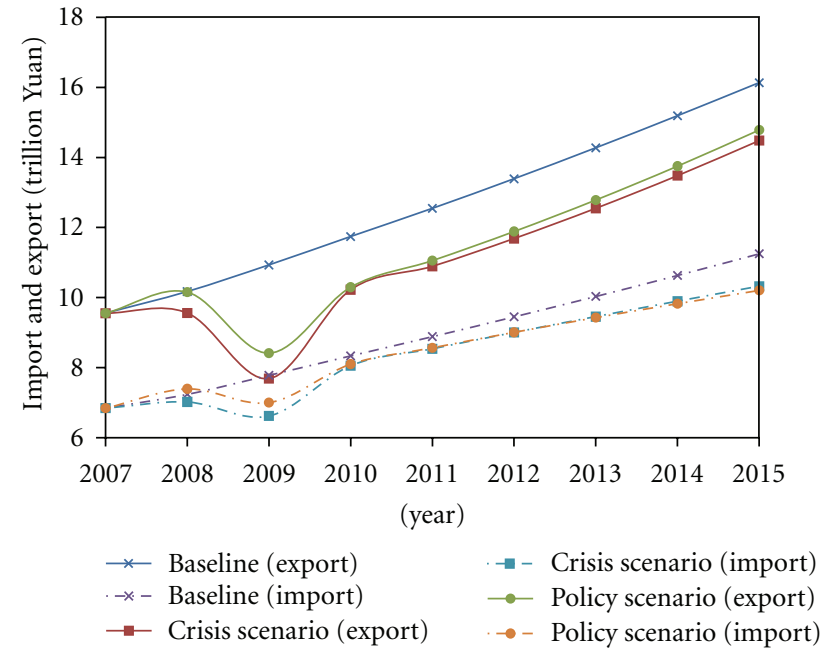

FiguRE 4: Import and export in different scenarios.

import are small with the policy of enlarging investment. Similar to crisis scenario, total import and total export begin to rebound and rise quickly in 2010 and then tend to increase steady from 2011. Although the growth rate of total export under crisis scenario and policy scenario are higher than baseline, the absolute amount appear 1-2 trillion Yuan lower during the period of 2011-2015.

Under baseline scenario, total net export keeps increasing from 2.71 trillion Yuan in 2007 to 4.88 trillion Yuan in 2015 , while the growth rate goes to decline gradually as time passes by, which decreases from $8.2 \%$ in 2008 to $7.1 \%$ in 2015. Net export decreases significantly in 2009 under crisis scenario and policy scenario, while it starts to increase close to the baseline level after financial crisis. With investment policy, net export raises a little bit faster compared to crisis scenario. Similar to the tendency of total export, net export grows much faster from the very low level in 2009 under crisis scenario and policy scenario compared to baseline in post-crisis period. Whereas the absolute amount are 0.7 trillion and 0.3 trillion Yuan lower than baseline in 2015, respectively.

The above results demonstrate that although investment policy stimulates the economic development greatly, it has limited impact on import and export. Tables 1 and 2 display the changes of import and export quantity in import or export intensive sectors in 2009 and 2015 under policy scenario.

In comparison with baseline, export quantities of most export intensive sectors drop by over $15 \%$ in 2009, especially in Instruments Meters Cultural and Office Machinery sector, Electric Equipment and Machinery, Electronic and Telecommunication Equipment sector, and Textile Industry sector, whose reduction rate achieve more than $18 \%$. As time goes on, export quantities in different sectors gradually tend to approach the baseline level, and the export change rate in policy scenario compared to baseline are mainly concentrated around $-8 \%$ in 2015.

Import quantities of most import intensive sectors are near or over $10 \%$ lower than baseline level in 2009, among

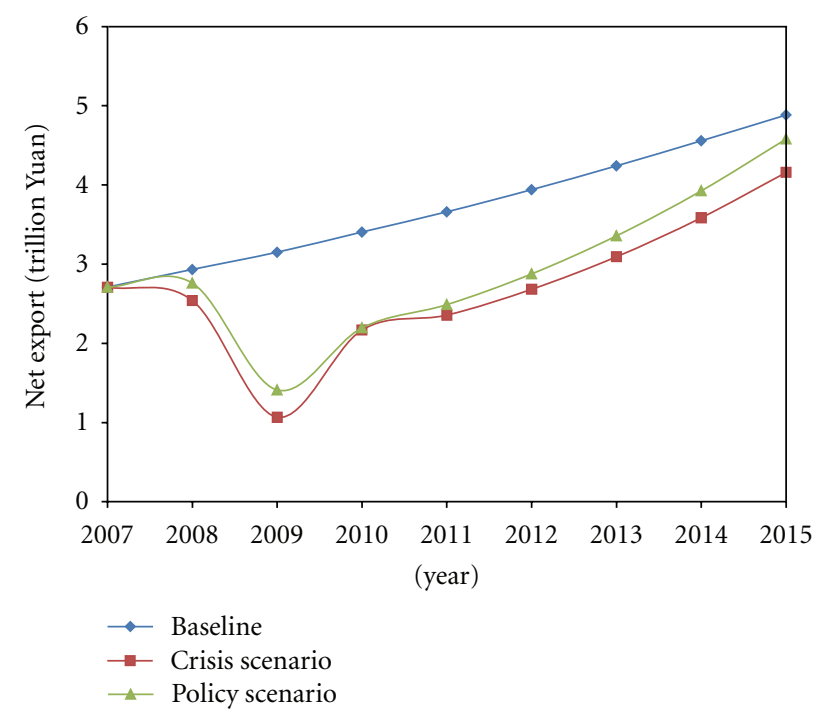

Figure 5: Net export in different scenarios.

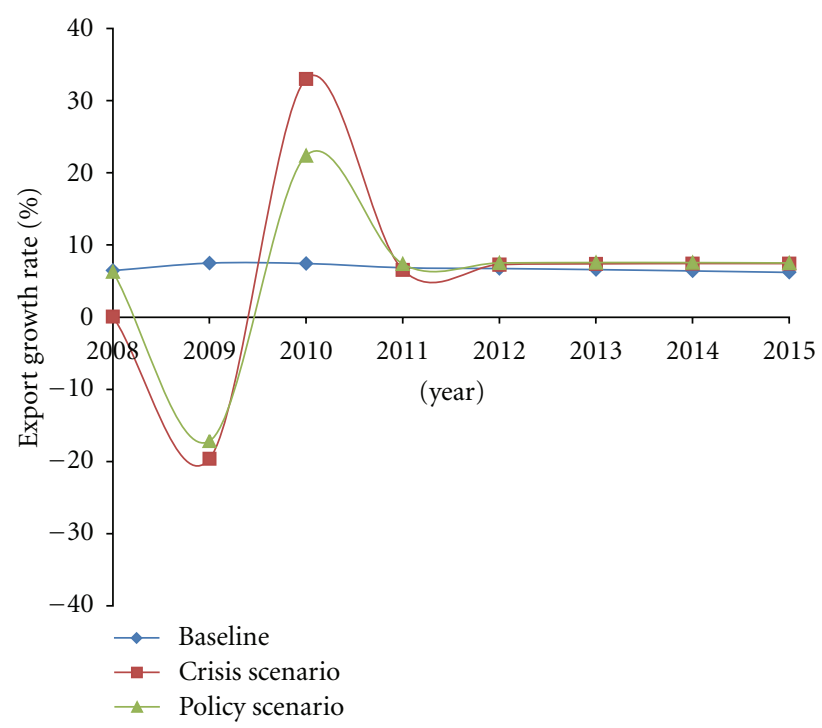

FIgURE 6: Export growth rate in different scenarios.

which, energy extraction sectors are affected relatively more seriously. The differences of import quantities between policy scenario and baseline scenario in most import intensive sectors tend to decrease through time.

4.1.3. Consumption and Income. It appears that the variation of final consumption growth rate among three scenarios is less radical compared with net export and GDP growth rate. In the scenario of baseline, total final consumption grows from 13.2 trillion Yuan in 2007 to 27.2 trillion Yuan in 2015 (Figure 8). It experiences a highest increase in 2009, with a growth rate of $11.3 \%$ in 2009, and then falls to $8.5 \%$ in 2015 . Final consumption growth rate drops to $6.85 \%$ in 2009 due to the financial crisis. Whereas it rebounds to increase to $7.56 \%$ in 2012 and declines to $6.63 \%$ in 2015 . Boosted by the increased investment under policy scenario, the annual 
TABLE 1: Export change rate of sectors in policy scenario compared to baseline.

\begin{tabular}{ll}
\hline Sectors & Export change rate (\%) \\
\hline Electric equipment and machinery, electronic and telecommunication equipment & 2009 \\
Other services & -18.8 \\
Textile industry & -14.9 \\
General and special-purpose machinery manufacturing & -18.8 \\
Manufacture of clothes, leather, fur, feather and its products & -13.8 \\
Transport, storage, and postal telecommunication service & -16.2 \\
Smelting and pressing of ferrous metals & -14.7 \\
Metal products & -14.0 \\
Raw chemical materials and products & -15.2 \\
Transportation equipment & -15.3 \\
Instruments meters cultural and office machinery & -13.5 \\
Rubber products plastic products & -25.1 \\
Timber processing, bamboo, cane, palm, straw products, and furniture & -15.8 \\
Printing, recording media reproduction, stationery, education and sports goods & -15.5 \\
Manufacture of foods and beverage & -15.7 \\
\hline
\end{tabular}

Note: the above 15 sectors account for $91.5 \%$ of total export in 2007, and size down according to the share of export.

TABLE 2: Import change rate of sectors in policy scenario compared to baseline.

\begin{tabular}{lcc}
\hline Sectors & Import change rate (\%) \\
\hline Electric equipment and machinery, electronic and telecommunication equipment & 2009 & 2015 \\
Raw chemical materials and products & -8.7 & -8.6 \\
General and special-purpose machinery manufacturing & -15.4 & -3.7 \\
Other services & -5.7 & -6.5 \\
Crude oil extraction & -14.2 & -14.7 \\
Instruments meters cultural and office machinery & -5.1 \\
Manufacture of transport equipment & -5.1 \\
Ferrous metals mining and dressing & -10.1 \\
Nonferrous metals mining and dressing & -13.6 \\
Agriculture & -9.8 \\
Smelting and pressing of ferrous metals & -11.5 \\
Other machinery industry & -12.7 \\
Manufacture of foods and beverage & -9.3 \\
Natural gas extraction & -16.2 \\
Processing of petroleum and nucleus fuel & -11.6 \\
\hline
\end{tabular}

Note: the above 15 sectors account for $88.8 \%$ of total export in 2007 and size down according to the share of import.

growth rate of final consumption mainly distribute to the interval between $1.5 \%$ and $2 \%$ higher than crisis scenario and $1 \%$ lower than baseline.

The results show a similar change tendency of government income and household income (Figures 9 and 10). They both have an upward trend but a reduced growth rate till 2015 under baseline. Government income starts from 7.8 trillion Yuan in 2007 and then grows at an average annual rate of $10.4 \%$ to 17.2 trillion Yuan in 2015. Rural household income and urban household income are from 4.1 trillion Yuan and 13.3 trillion Yuan in 2007 to 12.4 trillion Yuan and 34.1 trillion Yuan in 2015, with an average growth rate of $14.9 \%$ and $12.5 \%$, respectively.
Government income and household income appear negative growth in 2009 affected by financial crisis. They decrease by $4.4 \%$ of government income, as well as $2 \%$ and $5.3 \%$ of rural household income and urban household income, which means a more significant impact on urban household than rural household. The growth rate of government income, rural household income, and urban household income are tending stability but a little lower than baseline after a bounce in 2010, with an average annual growth rate of $8.96 \%, 12.36 \%$, and $10.73 \%$ during 2011-2015. Stimulated by investment in 2009, government income, rural household income and urban household income rise at a certain extent and then grow as the similar tendency as baseline and crisis 


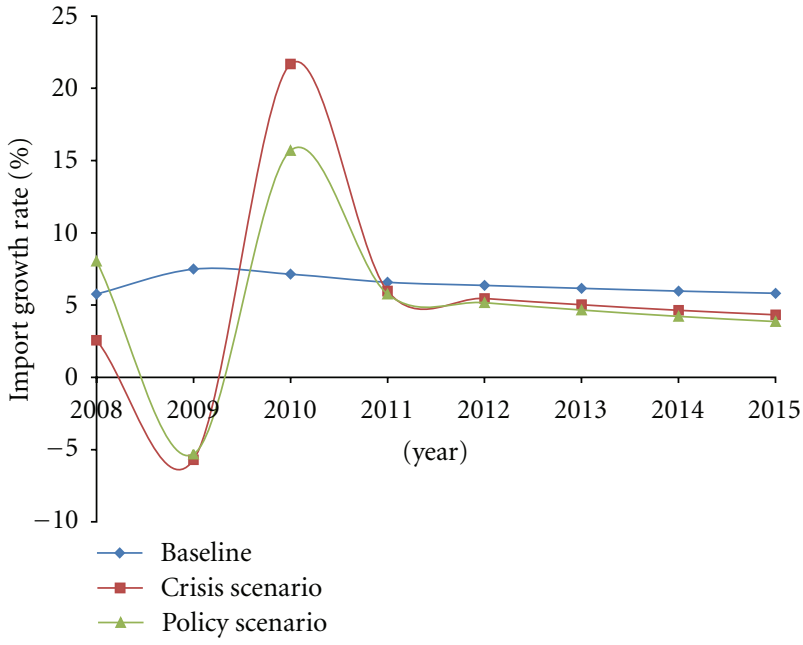

FiguRE 7: Import growth rate in different scenarios.

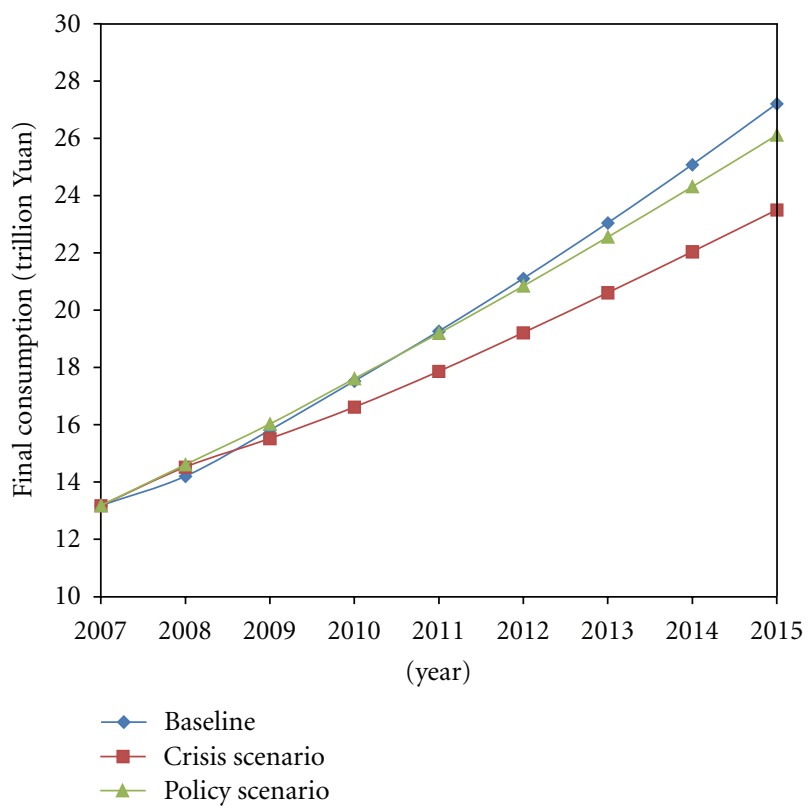

Figure 8: Final consumption in different scenarios.

scenario, which increase with an average annual rate of $8.92 \%, 12.66 \%$, and $10.70 \%$ from 2011 to 2015 , respectively.

4.1.4. GDP Composition. The predicted results show that the share of final consumption in GDP is getting higher, while net export and gross fixed capital formation account for a decreasing proportion with years roll on under baseline scenario (Table 3 ). Contrast with the decreasing contribution rate of gross fixed capital formation, the contributions from final consumption and net export to GDP growth tend to increase recently in baseline scenario. The proportional of net export to GDP resulted from financial crisis is simulated to reduce rapidly by 6 points of percentage compared with baseline in 2009. The share of gross fixed capital formation to GDP with investment enlarging policy is $4 \%$ higher than

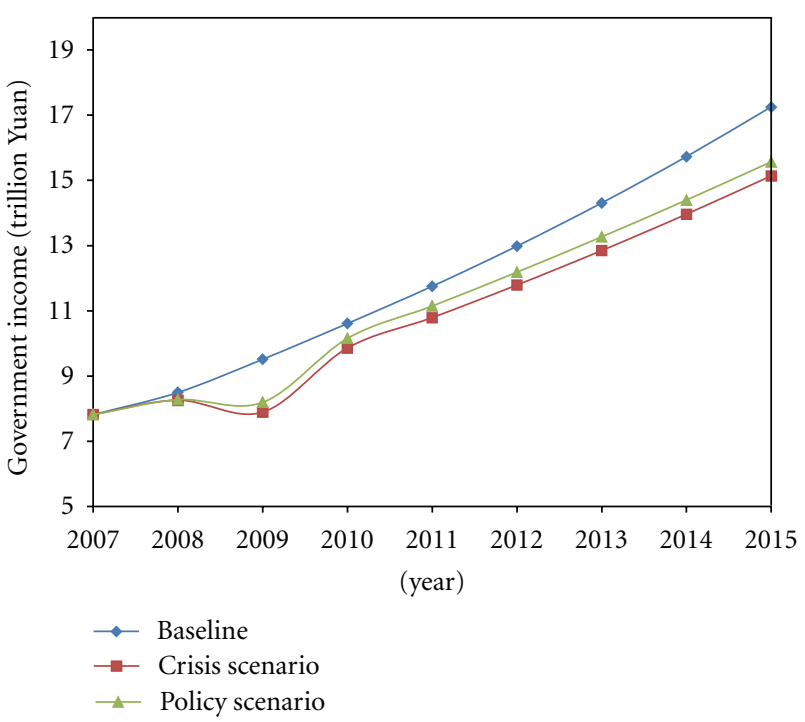

FIGURE 9: Government income in different scenarios.

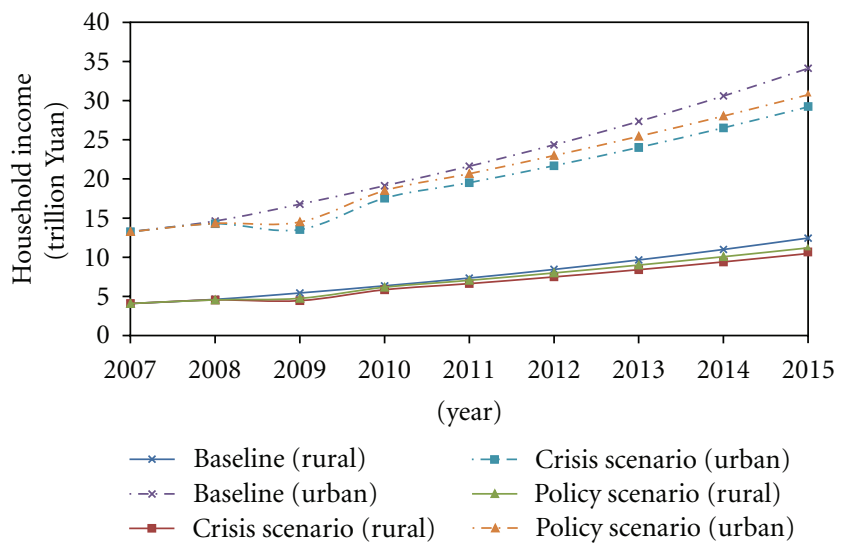

Figure 10: Household income under different scenarios.

baseline in 2009. Gross fixed capital formation increment accounts for $92.3 \%$ of GDP growth, while the net export experiences a negative contribution of $-44.9 \%$ to GDP growth (Table 4). It can be identified that GDP growth is primary driving by investment under policy scenario.

Despite the net export account for lower share of GDP under crisis scenario and policy scenario compared to baseline, the contributions to GDP growth from incremental net export tend to be higher with the gradual recovery of import and export through time. Investment increasing policy stimulates consumption and leads to a larger contribution from final consumption to GDP growth in comparison with crisis scenario in the near post-crisis term.

Table 5 displays some comparisons between the actual data and simulation results. It can be identified that the results under policy scenario are similar with the actual data in 2009. The actual data illustrate again that stimulus package played a significant role in stabilizing economic growth. However, there are some differences between the results under policy scenarios and the actual data in 2010. 
TABLE 3: GDP composition by expenditure approach in different scenarios (\%).

\begin{tabular}{lcccccc}
\hline & & 2007 & 2009 & 2011 & 2013 & 2015 \\
\hline \multirow{3}{*}{ Baseline } & Final consumption & 48.5 & 48.4 & 49.5 & 50.7 & 51.9 \\
& Gross fixed capital formation & 41.5 & 42.0 & 41.1 & 40.0 & 38.8 \\
& Net export & 10.0 & 9.6 & 9.4 & 9.3 & 9.3 \\
\hline \multirow{3}{*}{ Crisis scenario } & Final consumption & 48.5 & 51.5 & 49.6 & 49.5 & 49.2 \\
& Gross fixed capital formation & 41.5 & 45.0 & 43.9 & 43.1 & 42.1 \\
& Net export & 10.0 & 3.5 & 6.5 & 7.4 & 8.7 \\
\hline \multirow{3}{*}{ Policy scenario } & Final consumption & 48.5 & 49.6 & 49.6 & 50.2 & 42.3 \\
& Gross fixed capital formation & 41.5 & 46.0 & 44.0 & 40.6 \\
& Net export & 10.0 & 4.4 & 6.4 & & 7.5 \\
\hline
\end{tabular}

TABLE 4: Contribution to GDP growth in different scenarios (\%).

\begin{tabular}{|c|c|c|c|c|c|}
\hline & & 2009 & 2011 & 2013 & 2015 \\
\hline \multirow{3}{*}{ Baseline } & Final consumption & 53.4 & 56.3 & 58.2 & 59.6 \\
\hline & Gross fixed capital formation & 39.4 & 35.4 & 32.8 & 31.2 \\
\hline & Net export & 7.2 & 8.3 & 9.0 & 9.1 \\
\hline \multirow{3}{*}{ Crisis scenario } & Final consumption & 143.1 & 49.6 & 48.3 & 46.6 \\
\hline & Gross fixed capital formation & 168.8 & 43.0 & 37.4 & 35.1 \\
\hline & Net export & -211.9 & 7.5 & 14.2 & 18.3 \\
\hline \multirow{3}{*}{ Policy scenario } & Final consumption & 52.7 & 54.5 & 53.8 & 52.7 \\
\hline & Gross fixed capital formation & 92.3 & 35.4 & 31.1 & 28.2 \\
\hline & Net export & -44.9 & 10.1 & 15.1 & 19.1 \\
\hline
\end{tabular}

Compared with the actual data, the contribution to GDP growth from gross fixed capital formation is lower, while the contribution from net export and final consumption appear higher under policy scenario. The main reason is time lag of stimulus policy effects. Due to ongoing projects need to be supported by subsequent investment, a big scale of credit funds ( 7.5 trillion Yuan) was input into the economy in 2010. It leads to relatively higher contribution to GDP of fixed capital formation in 2010. However, the shock from stimulus policy is only imposed in 2009 under policy scenario The simulation did not take consideration of the impacts of subsequent credit funds impact on gross fixed capital formation in 2010. Moreover, the influence of the appreciation of RMB on import and export is not captured in this work.

4.2. Energy Consumption and $\mathrm{CO}_{2}$ Emission in Different Scenarios. The dynamic CGE model is also applied to explore the impact of expanding investment on energy saving and $\mathrm{CO}_{2}$ mitigation. The predicted total energy consumption are $4.25,4.02$, and 4.26 Gtce, as well as total $\mathrm{CO}_{2}$ emission are $8.37,8.02$, and $8.42 \mathrm{Gt}$ in 2015 under baseline, crisis scenario and policy scenario, respectively (Figures 11 and 12). Among which, high energy intensive sectors, including Production and Supply of Thermal Power Generation and Heat, Smelting and Pressing of Ferrous Metals, Transport, Storage, and Postal Telecommunication Service, Raw Chemical Materials and Products, Manufacturing of Cement, Lime and Plaster, Construction, Processing of Petroleum and Nucleus Fuel, Manufacture of Nonmetallic Mineral Products, account for approximately $82 \%$ in total $\mathrm{CO}_{2}$ emission (Table 6).
Figures 13 and 14 display the energy consumption intensity and $\mathrm{CO}_{2}$ emission intensity under different scenarios. Both energy intensity and $\mathrm{CO}_{2}$ intensity appear a gradual decline along with the time due to the growth of TFP, but the variations exist among different scenarios. Under baseline scenario, energy consumption per unit GDP is decrease by $13.2 \%$, from 0.93 tce/10000 Yuan in 2007 to 0.81 tce/10000 Yuan in 2015. In the meanwhile, $\mathrm{CO}_{2}$ emission per unit GDP is from $2.02 \mathrm{t} / 10000$ Yuan in 2007 to $1.59 \mathrm{t} / 10000$ Yuan in 2015 , with a drop rate by $21.2 \%$. Owing to the low productivity, energy consumption intensity and $\mathrm{CO}_{2}$ emission intensity appear to increase in 2009 under financial crisis, and then falling to 0.84 and 1.68 in 2015 , which are $3.9 \%$ and $5.2 \%$ higher than baseline, respectively. Energy consumption intensity and $\mathrm{CO}_{2}$ emission intensity with investment policy are also above the level of baseline. The results show the energy consumption intensity and $\mathrm{CO}_{2}$ emission intensity are 0.83 tce/10000 Yuan and $1.63 \mathrm{t} / 10000$ Yuan in 2015, which are $1.9 \%$ and $2.3 \%$ higher than baseline.

It can be identified that relying on the policy of increasing investment response to financial crisis brings a higher energy consumption intensity and $\mathrm{CO}_{2}$ emission intensity compared to baseline, which enhances the difficulty for energy saving and $\mathrm{CO}_{2}$ mitigation.

Actually, energy intensity has reduced $19.1 \%$ during the period from 2005 to 2010 . It should be noticed that simulations in this paper do not reflect the real condition with all energy saving policies but only aim to assess the effects on energy and $\mathrm{CO}_{2}$ emission due to expanding investment policy. In the period of "Chinese twelfth five year plan" 
TABLE 5: Comparison between the actual data and simulation results (\%).

\begin{tabular}{|c|c|c|c|c|c|c|}
\hline & & & Actual data & Baseline & Crisis scenario & Policy scenario \\
\hline \multirow{7}{*}{2009} & \multicolumn{2}{|c|}{ GDP growth rate } & 9.1 & 10.2 & 2.4 & 9.1 \\
\hline & \multirow{3}{*}{ GDP composition } & Final consumption & 48.6 & 48.4 & 51.5 & 49.6 \\
\hline & & Gross fixed capital formation & 46.7 & 42.0 & 45.0 & 46.0 \\
\hline & & Net export & 4.7 & 9.6 & 3.5 & 4.4 \\
\hline & \multirow{3}{*}{ Contribution to GDP growth } & Final consumption & 45.4 & 53.4 & 143.1 & 52.7 \\
\hline & & Gross fixed capital formation & 95.2 & 39.4 & 168.8 & 92.3 \\
\hline & & Net export & -40.6 & 7.2 & -211.9 & -44.9 \\
\hline \multirow{7}{*}{2010} & \multicolumn{2}{|c|}{ GDP growth rate } & 10.3 & 9.6 & 11.1 & 10.8 \\
\hline & \multirow{3}{*}{ GDP composition } & Final consumption & 47.6 & 48.9 & 49.6 & 49.2 \\
\hline & & Gross fixed capital formation & 47.5 & 41.6 & 43.9 & 44.7 \\
\hline & & Net export & 4.9 & 9.5 & 6.5 & 6.1 \\
\hline & \multirow{3}{*}{ Contribution to GDP growth } & Final consumption & 37.3 & 54.7 & 32.8 & 45.3 \\
\hline & & Gross fixed capital formation & 54.8 & 37.2 & 34.4 & 32.3 \\
\hline & & Net export & 7.9 & 8.1 & 32.9 & 22.4 \\
\hline
\end{tabular}

Source: the actual data come from: http://www.stats.gov.cn/.

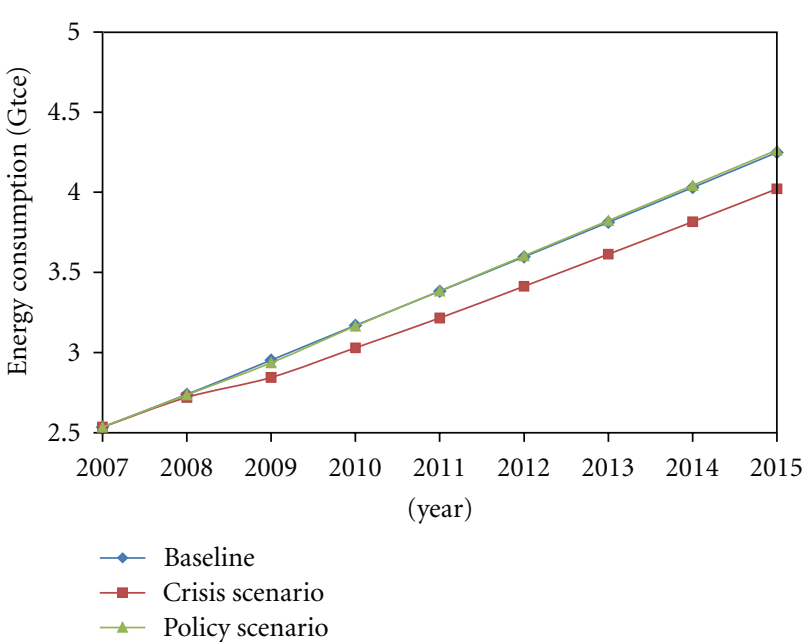

FIGURE 11: Energy consumption in different scenarios.

(from 2011 to 2015), the simulated $\mathrm{CO}_{2}$ emission intensity are forecasted to fall by $11.8 \%, 10.0 \%$, and $10.2 \%$ under baseline scenario, crisis scenario and policy scenario, respectively, which imply that Chinese government should adopt additional $\mathrm{CO}_{2}$ mitigation policies under the pressure of $\mathrm{CO}_{2}$ intensity target towards 2020 .

\section{Conclusions}

This paper constructs a Chinese dynamic CGE model to get the possible near term economic development pathways under different scenarios, and assess the contribution of investment expansion policy to Chinese economic growth. Moreover, taking into account the possible problems of over capacity owing to enlarging investment, energy consumption, and $\mathrm{CO}_{2}$ emission are also compared among different scenarios.

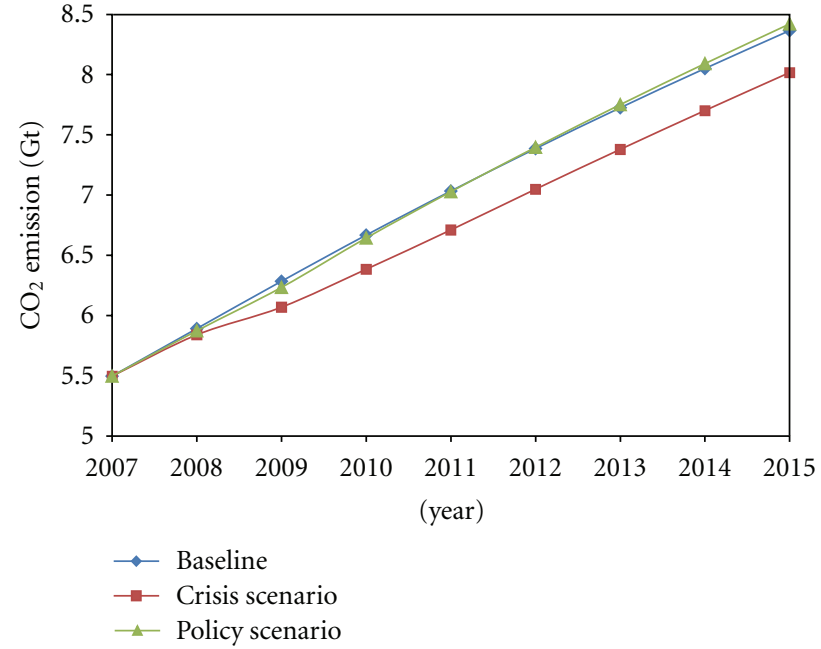

FIGURE 12: $\mathrm{CO}_{2}$ emission in different scenarios.

The results show that GDP growth rate falls to $2.36 \%$ in 2009 without any corresponding policies due to a sharp decrease of export and import as well as productivity affected by financial crisis. The policy of expanding investment can significantly alleviate the great impact on GDP growth and relieve the fluctuation in economy. It can increase economic growth rate by $6.74 \%$ to $9.10 \%$ in 2009 , among which, the gross fixed capital formation plays an important role in GDP growth. A higher TFP, together with final consumption and net export, is driving by investment. Moreover, it can also alleviate the range of variations about the growth rate of consumer and government income as well as final consumption.

Actually, the newly added investment in 2009 was 5.2 trillion Yuan, including part from the natural growth under business as usual, and part from stimulus policies respond to financial crisis. The average annual growth rate for total 
TABLE 6: $\mathrm{CO}_{2}$ emission in high energy intensive sectors in 2015 (Gt).

\begin{tabular}{|c|c|c|c|}
\hline & Baseline & Crisis scenario & Policy scenario \\
\hline Production and Supply of Thermal Power Generation & 3.42 & 3.3 & 3.45 \\
\hline Smelting and Pressing of Ferrous Metals & 1.32 & 1.3 & 1.34 \\
\hline Transport, Storage, and Postal Telecommunication Service & 0.72 & 0.68 & 0.73 \\
\hline Raw Chemical Materials and Products & 0.41 & 0.4 & 0.42 \\
\hline Manufacturing of Cement, Lime, and Plaster & 0.34 & 0.35 & 0.35 \\
\hline Production and Supply of Heat & 0.3 & 0.29 & 0.3 \\
\hline Construction & 0.11 & 0.11 & 0.11 \\
\hline Processing of Petroleum and Nucleus Fuel & 0.11 & 0.1 & 0.11 \\
\hline Manufacture of Nonmetallic Mineral Products & 0.1 & 0.1 & 0.11 \\
\hline Subtotal & 6.85 & 6.62 & 6.92 \\
\hline Share in total emission (\%) & 81.8 & 82.6 & 82.2 \\
\hline
\end{tabular}

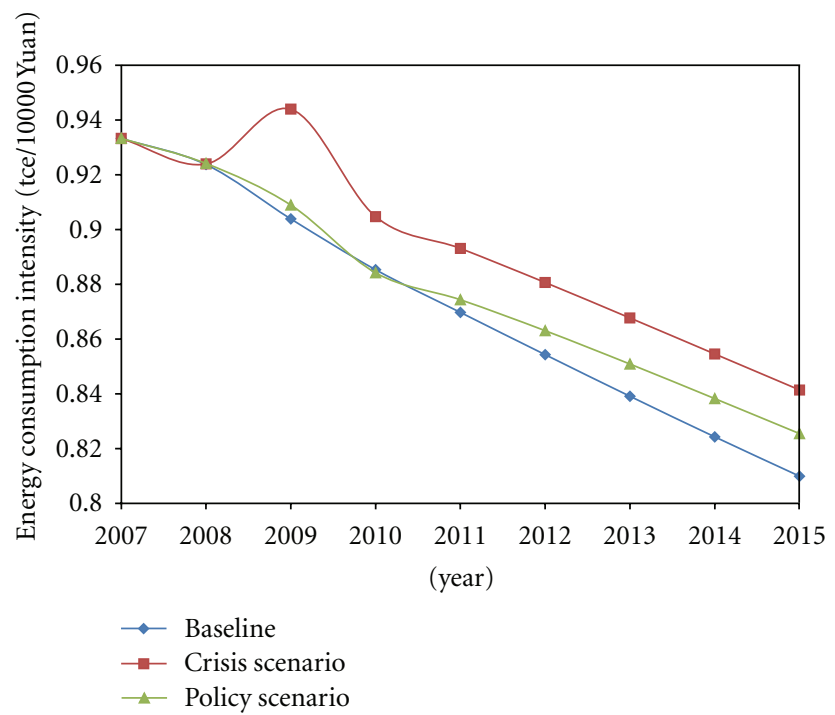

FIGURE 13: Energy intensity in different scenarios.

investment in fixed assets was $20.6 \%$ from 2000 to 2008 , among which $15.7 \%$ for $2000-2003$ and $25.5 \%$ for $2004-$ 2008. Affected by financial crisis, natural growth of investment in 2009 seemed lower than the period of overheated economy without economic stimulated plan. Whereas allowing for inertia of economic activity, the natural growth rate of investment in 2009 was postulated as $18 \%$. The difference between the actual investment and investment with natural growth can be treated as incremental investment owing to stimulated policies. Gross fixed capital formation increased 2.5 trillion Yuan from 2008 to 2009, among which, 1.3 trillion Yuan was deserved from the incremental investment. The total gross fixed capital formation accounted for $92.3 \%$ to GDP growth in 2009.

The investment enlargement policy brings the economic growth close to baseline level gradually in the near post-crisis period, with an average GDP annual growth rate of $7.94 \%$, $7.38 \%$, and $7.61 \%$ under baseline scenario, crisis scenario, and policy scenario, respectively. Net export is also toward the baseline level through time with policy. Although the

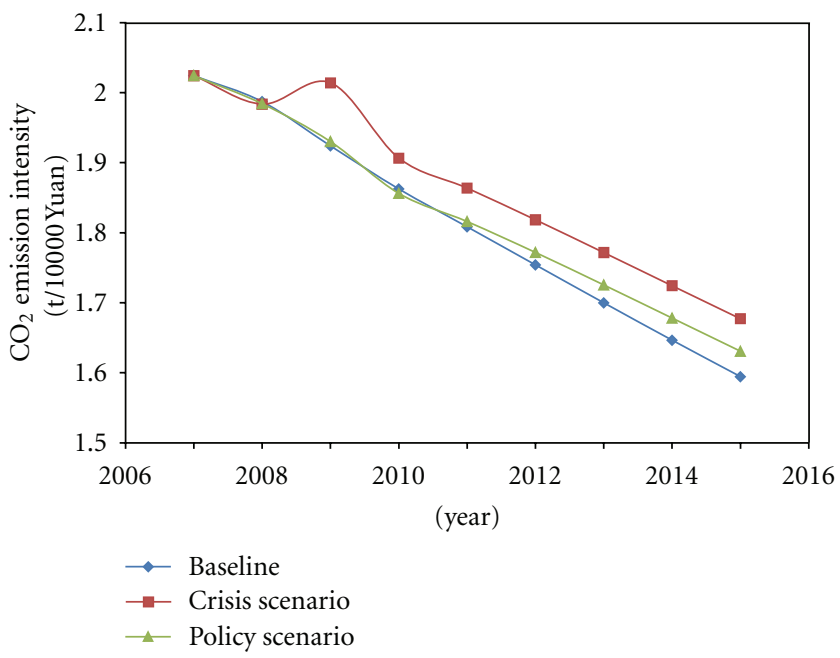

FIGURE 14: $\mathrm{CO}_{2}$ emission intensity in different scenarios.

net export account for lower share of GDP under crisis scenario and policy scenario versus baseline, the contribution to GDP growth from incremental net export tend to be higher with the gradual recovery of import and export. Final consumption keeps growing but with a decreasing growth rate as time passes by. The expanding investment stimulates the annual growth rate of final consumption to be $1.5 \%-2 \%$ higher than crisis scenario but $1 \%$ lower than baseline, and it leads a larger contribution from final consumption to GDP growth in comparison with crisis scenario in near term.

However, the increasing investment policy also brings new problems. It induces higher energy consumption intensity and $\mathrm{CO}_{2}$ emission intensity, which are $1.9 \%$ and $2.3 \%$ more than baseline in 2015, respectively. It can be observed that the investment enlarging policy enhances the difficulty for energy saving and $\mathrm{CO}_{2}$ mitigation.

It should be noticed that this paper focuses on the effects of expanding investment policy on economic growth but not put attention to the impacts of monetary policy on macroeconomic consequences. In fact, the moderately loose monetary policy has led to a huge increase in loan. It is thought that excessive fluidity has posed impacts on inflation 
in post-crisis China. The analysis on such issue is not involved in this paper.

\section{Acknowledgments}

This work was supported by Planning and Strategic Research Projects of Chinese Academy of Science on "Cause of American Financial Crisis and Impact on China's Economy" hosted by Siwei Cheng. The authors thank Siwei Cheng for guidance and suggestions on the paper.

\section{References}

[1] J. Wu, "Saving, investment and economic growth-dynamic analysis of Chinese capital supply and demand," Economic Research Journal, vol. 11, pp. 29-38, 1999.

[2] J. Q. Liu and H. C. Yu, "Positive analysis of causal relationship between fixed investment and economic growth in China's economy," Statistical Research, vol. 19, no. 1, pp. 26-29, 2002.

[3] W. Wang, "The studies on the dynamic relationship among savings, investment and economic growth-empirical research of China from 1952 to 2006," Nankai Economic Studies, no. 2, pp. 105-125, 2008.

[4] W. G. Zhang and Y. J. Hou, "The effects of local government investment on economic growth and employment: evidence from transitional China," Ecological Economy, vol. 5, no. 1, pp. 28-37, 2009.

[5] F. Wang, S. Guo, and M. Ezaki, "Labor migration and regional development in China: a regional CGE analysis," China Economic Quarterly, vol. 5, no. 4, pp. 1067-1090, 2006.

[6] N. Li, M. J. Shi, and F. Wang, "Roles of regional differences and linkages on Chinese regional policy effect: based on an eightregion CGE model for China," System Engineering Theory \& Practice, vol. 29, no. 10, pp. 35-44, 2009.

[7] W. Ding, "Reflections of 4 trillion of Yuan investment," Legal System and Society, no. 2, p. 248, 2009.

[8] S. L. Zhang, "The progress and results of 4 trillion Yuan of investment," Macroeconomic Management, no. 12, pp. 29-31, 2009.

[9] X. P. Zhang, "Implementation and impact of the expansionary fiscal policy of 4 trillion RMB," Beijing College Political Science and Law, no. 1, pp. 88-91, 2009.

[10] X. Wang and R. Lu, "Four trillion investment plan under crisis: short-term effects and long-term influence," Journal of Sun Yatsen University, vol. 49, no. 4, pp. 180-188, 2009.

[11] Y. Sun, Y. X. Zhu, and Z. Wang, "Policy simulation on national large scale investment program based on the impaction of financial crisis," Geographical Research, vol. 29, no. 5, pp. 789800,2010 .

[12] H. Lofgren, R. Harris, and S. Robinson, A standard Computable General Equilibrium (CGE) Model in GAMS, International Food Policy Research Institute, 2002.

[13] Y. J. Wu and X. W. Xuan, Economic Theory of Environmental Tax and Analysis of their Application in China, Beijing, China, Economic Science Press, 2002.

[14] S. Paltsev, J. M. Reilly, H. D. Jacoby et al., "The MIT Emissions Prediction and Policy Analysis (EPPA) Model: Version 4," MIT, 2005, http:// globalchange.mit.edu/pubs/abstract .php?publication_id=697.

[15] H. S. Eggleston, L. Buendia, K. Miwa, T. Ngara, and K. Tanabe, Eds., 2006 IPCC Guidelines for National Greenhouse Gas Inventories, Prepared by the National Greenhouse Gas Inventories Programme, Institute for Global Environmental Strategies, Kanagawa, Japan, 2006.
[16] L. L. Sun and R. E. Ren, "The estimation of Chinese capital input and total factor productivity," The Journal of World Economy, no. 12, pp. 5-15, 2005.

[17] X. L. Wang, G. Fan, and P. Liu, "Transformation of growth pattern and growth sustainability in China," Economic Research Journal, no. 1, pp. 4-16, 2009. 


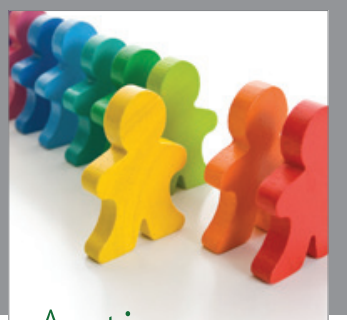

Autism

Research and Treatment
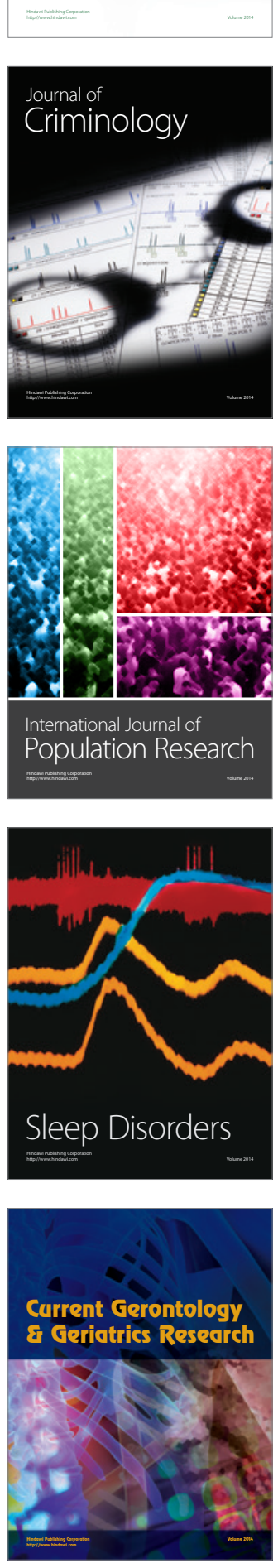
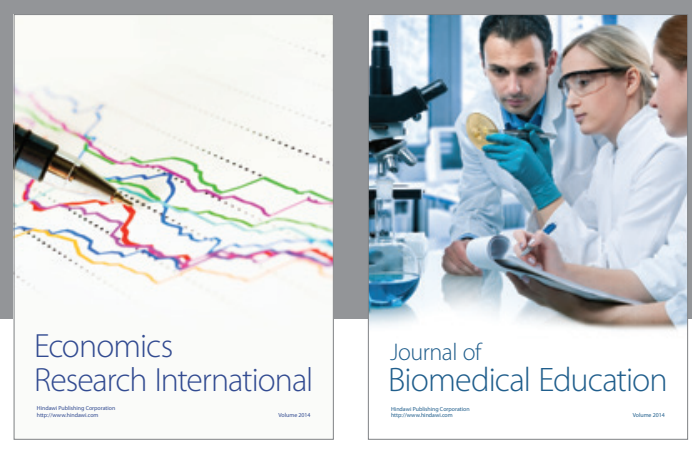

Journal of

Biomedical Education

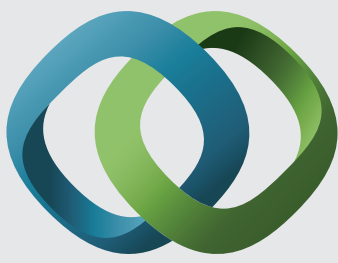

\section{Hindawi}

Submit your manuscripts at

http://www.hindawi.com
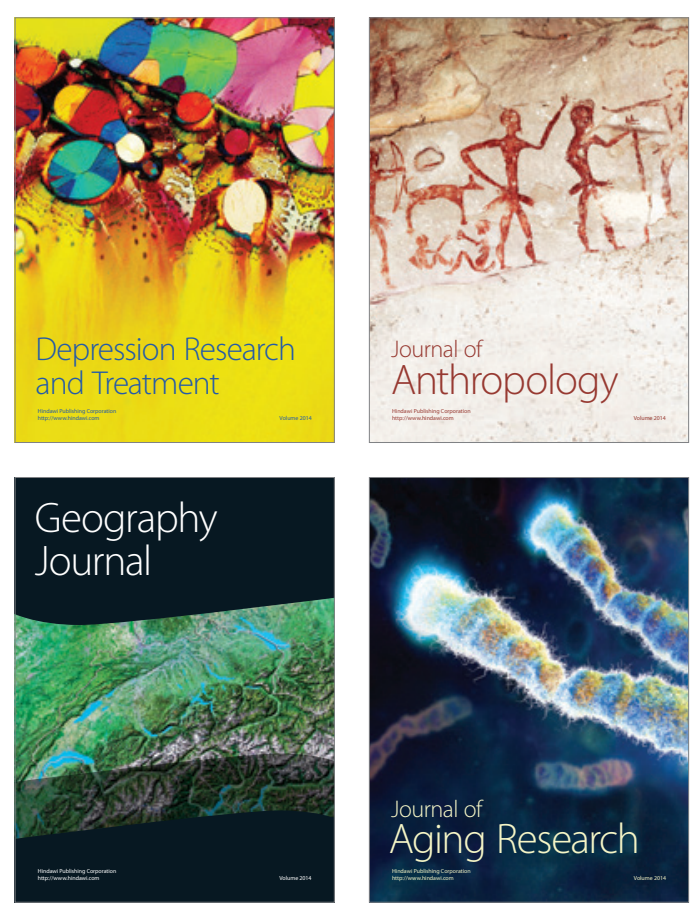

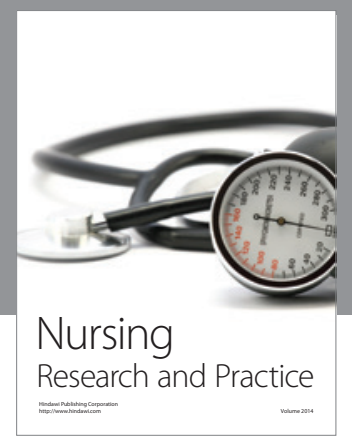

Nursing

Research and Practice

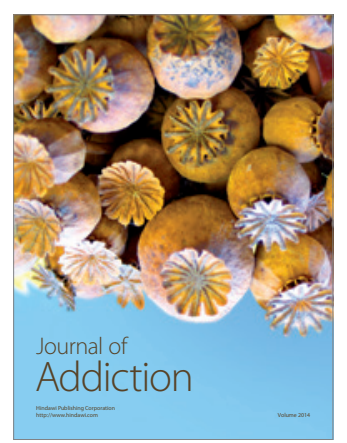

Child Development

Research

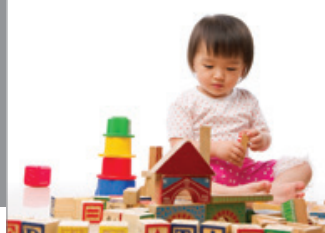

迥
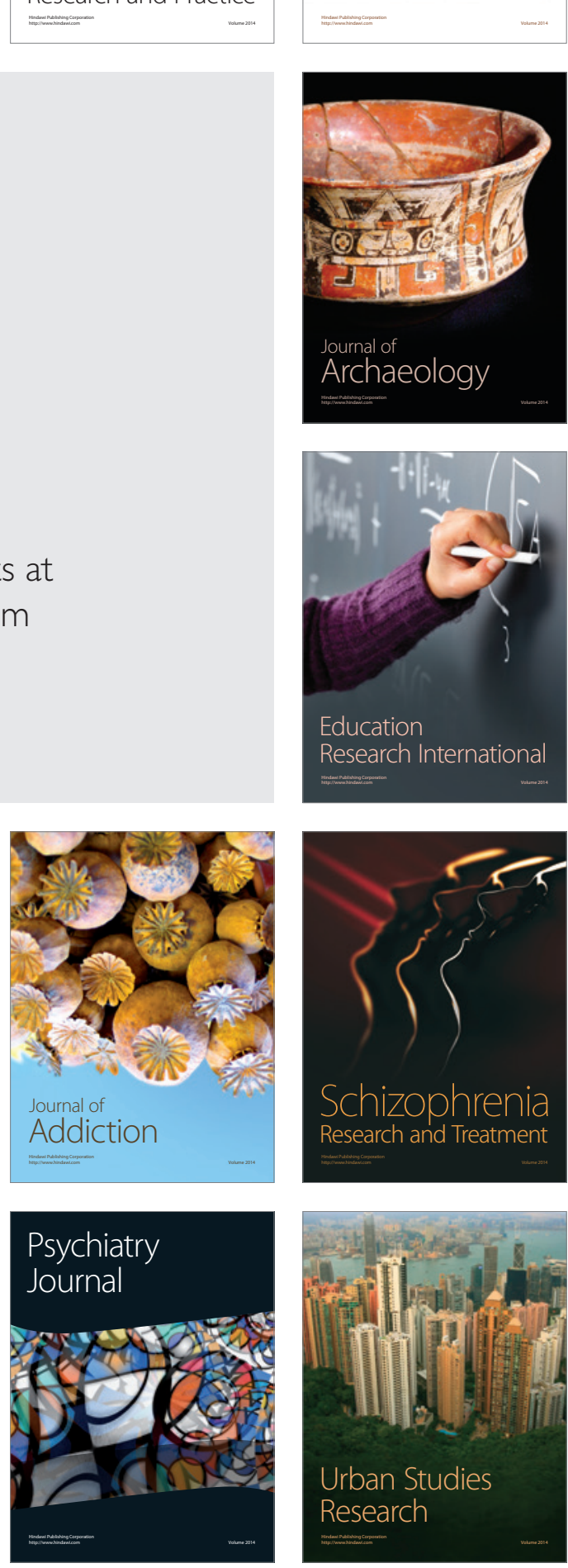